\title{
EDUCAÇÃO AMBIENTAL PARA O TURISMO SERTANEJO NO CARSTE DA FURNA DOS OSSOS, CEARÁ
}

\author{
Nágila Fernanda Furtado Teixeira ${ }^{(a)}$, Pedro Edson Face Moura ${ }^{(b)}$, Edson Vicente da \\ Silva ${ }^{(b)}$
}

(a) Mestranda em Desenvolvimento e Meio Ambiente-PRODEMA/Universidade Federal do Ceará (UFC),Email: fernandaft92@gmail.com

(b) Mestrando em Geografia/Universidade Federal do Ceará (UFC). Email: pedroedson18@ @mail.com

(c) Professor do Departamento de Geografia/Universidade Federal do Ceará (UFC). Email: cacauceara@gmail.com

Eixo: GEODIVERSIDADE, GEOARQUEOLOGIA E PATRIMÔNIO NATURAL

\section{Resumo}

O presente trabalho apresenta a experiência de uma série de atividades de Educação Ambiental realizadas com um grupo de moradores do Assentamento Macaco que convivem diretamente com o ambiente semiárido e a paisagem cárstica, potencialidade natural para o desenvolvimento do turismo sertanejo em Tejuçuoca-Ceará. A partir do diagnóstico, dos principais problemas ambientais da área denominada popularmente como "Parque" Furna dos Ossos que compreende uma geomorfologia cárstica formada por furnas e cavernas de metacalcário em 144 hectares, efetivou-se palestras sobre os aspectos geográficosfísicos do sertão cearense, enfatizando principalmente a geomorfologia da área, bem como palestras sobre a importância do manejo dos recursos naturais, conservação da caatinga, solo e água, culminando com a construção de matrizes ambientais. As atividades contaram com o engajamento e participação dos envolvidos, em que verificamos a compreensão dos mesmos no compromisso de valorizar e conservar o semiárido.

Palavras-chave: Educação Ambiental; paisagem cárstica; turismo sertanejo; conservação.

\section{Introdução}

A região semiárida cearense se caracteriza pela irregularidade pluviométrica, temperaturas altas e vegetação de caatinga, conforme classifica Ab'Saber (2003, p. 81) "o domínio dos sertões secos" que por possuírem características naturais peculiares, Depressão Sertaneja, inselbergs dentre outras, poderiam ser melhor preparados para fins de lazer, turismo e esportes.

No sertão centro-norte do Estado do Ceará, destaca-se Tejuçuoca que compreende uma área de $750,60 \mathrm{~km}^{2}$, a $144 \mathrm{~km}$ de distância da cidade de Fortaleza, possui 16.827 habitantes sendo $62,35 \%$ na zona rural e $37,65 \%$ urbana (IBGE, 2010). Nesse município encontra-se o "Parque" Furna dos Ossos, que embora receba essa denominação popular, não corresponde a uma unidade de conservação legalizada a nível federal, estadual ou municipal. Essa área apresenta $144 \mathrm{~km}$ de paisagem cárstica com furnas e cavernas formadas de metacalcário e surpreendente fauna e flora que compreendem $20 \%$ da Reserva Legal do Assentamento Macaco composto por 14 famílias. 
A paisagem cárstica da Furna dos Ossos corresponde a importante potencialidade para o desenvolvimento do turismo sertanejo, mas esse ambiente contém áreas degradadas, principalmente por queimadas e uso inadequado do solo provocando prejuízos, a fauna e flora e a população residente. Nessa perspectiva, faz-se relevante a Educação Ambiental, como teoria e prática corriqueira junto à população para sensibiliza-los quanto à importância de manter o ambiente equilibrado a partir de mudanças de atitudes e mentalidades sobre a relação sociedadenatureza, exploração dos recursos naturais e respeito à flora e fauna.

O desenvolvimento do presente artigo foi fundamentado na metodologia qualitativa através dos procedimentos de observação não participante, entrevistas semi-estruturadas com famílias do assentamento e funcionários da administração pública ligados a Secretaria da Cultura e do Turismo de Tejuçuoca. Segundo Marconi e Lakatos (2011, p. 267) “A metodologia qualitativa preocupa-se em analisar e interpretar aspectos mais profundos, descrevendo a complexidade do comportamento humano. Fornece análise mais detalhada sobre as investigações, hábitos, atitudes, tendências de comportamento etc".

A partir do diagnóstico desses problemas ambientais no "Parque" Furna dos Ossos realizou-se por um grupo de estudantes do curso de Geografia da Universidade Federal do Ceará-UFC, atividades de Educação Ambiental, fundamentada na concepção de Educação Ambiental Étnico-Social, com um grupo de moradores do Assentamento Macaco, voltadas a conscientização ambiental e valorização do semiárido a partir de seminários sobre a Geografia do Sertão-Cearense, apresentando as bases naturais e físicas do ambiente enfatizando principalmente o município de Tejuçuoca e a área cárstica.

Também realizou-se, palestras sobre a importância do manejo dos recursos naturais, conservação da caatinga, solo e água. Ademais, efetivou-se a construção, pelos moradores do assentamento, de matrizes ambientais com as potencialidades e fragilidades de Tejuçuoca, bem como soluções para os problemas ambientais diagnosticados.

\section{Paisagem cárstica como potencialidade natural para o turismo sertanejo em Tejuçuoca}

O turismo sertanejo é uma forma de lazer fundamentado em três pilares, o quadro natural, a cultura regional e a inclusão social da população residente (SEABRA, G., 2011). Essa atividade busca a interação entre o meio ambiente e o crescimento econômico, na valorização da cultura sertaneja e conservação das paisagens do sertão. Nesse sentido, o turismo sertanejo surge como uma alternativa para o desenvolvimento econômico, social, cultural e ambiental das comunidades sertanejas. 
"O turismo sertanejo prioriza a capacidade de suporte dos sistemas naturais e, ao mesmo tempo, incentiva o desenvolvimento dos sistemas econômico-sociais" (SEABRA, G., 2007, p. 33), assim, promove o desenvolvimento dessa atividade a partir de uma visão sustentável. Segundo Lícia Seabra (2012) o turismo por meio de uma visão sustentável busca a sustentabilidade ecológica a partir da conservação e uso racional dos recursos naturais, a sustentabilidade social e cultural por meio do fortalecimento e valorização da identidade da comunidade, bem como a sustentabilidade econômica com o desenvolvimento eficaz da economia de modo a assegurar recursos para as gerações futuras e a sustentabilidade política que possibilita a formação da cidadania dos indivíduos. De acordo com Beni (2000 aput SEABRA, 2011, p. 33):

O turismo sertanejo em razão dos seus princípios éticos no tocando à utilização dos recursos naturais e potencialidades culturais, insere-se no conceito de turismo sustentável, definido com base no sistema total ser humano/ meio ambiente, no qual a conservação ambiental é meta de importância igual à eficiência econômica e à justiça social para a geração de empregos, distribuição de renda e melhoria da qualidade de vida.

Silva (2007, p. 263) informa que as atividades turísticas relacionam-se diretamente aos atrativos: naturais e socioculturais. Sendo o primeiro relacionado às formas de paisagens e suas feições, cursos d' água, serras, fauna e flora. Enquanto o segundo vincula-se às manifestações de uma população, bebidas, comidas, artesanatos, festas, dentre outras. A partir desse preceito, identificou como principal atrativo natural referente ao desenvolvimento do turismo sertanejo em Tejuçuoca, o Parque Furna dos Ossos.

O "Parque" Furna dos Ossos, localizado no município de Tejuçuoca, recebe essa denominação popular, mas não é uma unidade de conservação legalizada, possui 144 hectares correspondendo a $20 \%$ da Reserva Legal do Assentamento Macaco, composto de 14 famílias que convivem diretamente com esse ambiente. Representa uma paisagem cárstica formada por furnas e cavernas de metacalcário, encontradas ao longo de $2 \mathrm{~km}$ de trilha, onde o visitante tem contato direto com a vegetação de caatinga e sua exuberante fauna e flora.

A paisagem cárstica do semiárido é um importante componente geoecológico, resultado da interação dos elementos naturais e humanos. Esta paisagem é marcada pelo relevo cárstico formados a partir da dissolução, principalmente das rochas carbonáticas e dolomíticas (CHRISTOFOLETTI, 2011). Essa morfologia forma uma incrível paisagem de imensa beleza cênica e uma área com vasta geodiversidade e biodiversidade, tornando-se uma importante potencialidade natural para o desenvolvimento do turismo sertanejo. 
Para a compreensão da "paisagem cárstica" deve-se compreender o carste em si. Segundo Lino (2009) o termo carste deriva do termo eslavo karst para designar as áreas de ocorrência de afloramentos calcários, significando "campos de padras calcárias", o termo remonta aos primeiros estudos em geologia em calcário no início do século XIX. No Brasil, embora já houvessem tentativas de explorações ambientes cárstico (espeleologia) desde do século XVII, foi apenas no século XIX que aparecem os primeiros textos e produções a respeito do tema (LINO, 2009).

O estudo da geomorfologia cárstica é necessário para compreender essa paisagem como um sistema ambiental. A geomorfologia cárstica é definida por Kohler (2012) como o estudo da forma, gênese e dinâmica dos relevos elaborados em rochas solúveis e menos solúveis.

Um ponto de destaque no "parque" é a trilha da harmonia, pois nesta, os visitantes tem a oportunidade de interagir e observar a grande diversidade de fauna e flora da caatinga, revelando-se assim uma importante ferramenta para a propagação da Educação Ambiental, bem como para a mudança de perspectiva em relação à caatinga quebrando o estereótipo de lugar feio e seco. É nessa perspectiva que se entende o "meio ambiente como uma visão global". Nesse ínterim, Rodriguez e Silva, (2013, p. 30) são categóricos em informar que,

O meio global define-se como sendo composto pelo entorno natural, os objetos e artefatos da civilização, e o conjunto de todos os fenômenos sociais e culturais que conformam e transformam os indivíduos e os grupos humanos (SOSA, 1995). Assim, considera-se que, no caso dos seres humanos, o meio ambiente é não só biofísico, mas também um meio social e econômico, ou seja, é também um meio cultural. Assim o meio ambiente, segundo esta visão, não é a sociedade nem a natureza, mas sim a inter-relação entre ambas. È comum, de acordo com esta visão, distinguirem-se no meio global, o meio natural ou físico, o meio construído e o meio social. Essa articulação realizase como resultado das interações entre as ofertas do suporte natural e as demandas dos grupos sociais. Esta é uma definição clássica, na qual divide-se o objeto (o meio) do sujeito (os seres humanos) e se da maior atenção aquilo que influi sobre o sujeito, ou seja, privilegia-se o meio como objeto. Como considera que o meio ambiente é o conjunto de fatores naturais e sociais e suas interações em um espaço e tempo dados, esta visão está perto da visão espacial.

Como atrativo natural as "Furnas são cavidades que aparecem nas encostas dos barracos formada geralmente pelo acúmulo de blocos de origem glaciária, ou de desmoronamento ou, ainda por dissolução. São formadas por blocos de granito e gnaisse que desmoronaram da encosta.” (GUERRA, 1972, p. 194). No contexto da paisagem cárstica, destaca-se também as cavernas, definidas como "Aberturas subterrâneas de dimensões muito variáveis que pode ser formada por dissolução e/ou desabamento, quando está presente em rochas de natureza calcária ou simplesmente por desabamento quando está presente em arenito [...]" (SUGUIO, 1998, p. 134). 
XVII Simpósio Brasileiro

de Geografia Fisica Aplicada

I Congresso Nacional

de Geografia Física
OS DESAFIOS DA GEOGRAFIA FÍSICA NA FRONTEIRA DO CONHECIMENTO

Instituto de Geociências - Unicamp

Campinas - SP

28 de Junho à 02 de Julho de 2017

Furna dos Ossos divide-se em sete furnas, Índio, Acauãs (Figura 1), Veados, Sino, Jardim, Lopes e Mesa são formações dotadas de misticismos e crenças pela população local. Acredita-se que nessas furnas, durante o período correspondente ao círculo da carne e do couro no Nordeste que coincide com as primeiras atividades do banditismo social ou cangaço, os bandos de cangaceiros utilizavam as furnas como residências temporárias, ou como áreas de emboscada. Embora esse conhecimento tradicional da região seja um dos atrativos das sete furnas, é necessário um estudo arqueológico aprofundado que comprovem essas histórias.

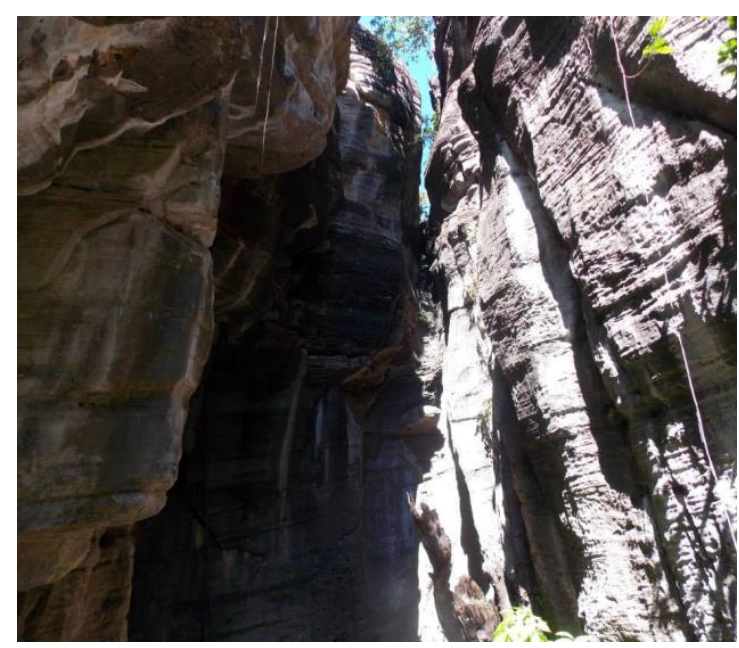

Figura 1- Furna do Acauãs, Tejuçuoca.

Fonte- MOURA, 2014.

Mesmo com toda a beleza e exuberância da área é nítido os problemas ambientais decorrentes de manejos inadequados dos recursos naturais como o desgaste do solo e desmatamento. Os problemas ambientais no sertão cearense, principalmente de ordem antrópica são fruto do processo histórico de uso e ocupação do território cearense, o sertão foi caracterizado pela pecuária extensiva, a monocultura do algodão e da cana-de-açúcar, agricultura de subsistência, o extrativismo vegetal e animal que ocasionaram o desmatamento da vegetação original e queimadas para o surgimento de pastagens para o gado e implantação de cultivos. Essas atividades socioeconômicas provocaram a perda progressiva dos solos e o surgimento de voçorocas e assoreamento dos cursos d'água (PEREIRA; SILVA, 2007).

No bioma caatinga a degradação decorre das queimadas, caça predatória e desmatamentos para a produção de madeira, lenha e carvão, "atualmente restam apenas 53\% da cobertura original, distribuídos em fragmentos remanescentes de matas, onde originalmente a Caatinga cobria uma área de 1 milhão de Km²"(ASSOCIAÇÃO CAATINGA, 2012, p. 50). 
A regulação da paisagem cárstica Furna dos Ossos como uma unidade de conservação de uso sustentável é imprescindível para a conservação dos recursos naturais da área, servindo como mecanismo legal de proteção da natureza: solos, recursos hídricos, fauna e flora e manutenção do equilíbrio natural dos ecossistemas e geossistemas. Mesmo não sendo legalizada, a área é conhecida popularmente como parque, recebendo visita de escolas, universidades e turistas interessados no contato com a natureza, pesquisa e lazer.

\section{Turismo sertanejo e Educação Ambiental: abordagem reflexiva}

O desenvolvimento do turismo sertanejo que se fundamenta no tripé: paisagem natural, desenvolvimento social e resgate cultural deve ser potencializado pela Educação Ambiental, através da sensibilização dos envolvidos quanto a conservação da natureza e superação dos problemas ambientais decorrentes da exploração dos recursos naturais. No caso de Tejuçuoca, a Educação Ambiental surge como uma ferramenta para melhorar o Parque Furna dos Ossos, mitigando a degradação do solo e da vegetação a partir da inserção teórica e prática no cotidiano dos moradores desse ambiente.

A Educação Ambiental como uma educação voltada à discussão das questões ambientais e sociais do planeta encontra-se diretamente relacionada à sustentabilidade, assim como o turismo sertanejo que busca o desenvolvimento econômico da localidade juntamente com a conservação e valorização do patrimônio natural. Nesse sentido, ressalta-se a importância da Educação Ambiental não apenas nos meios formais e institucionalizados, mas também nos outros espaços sociais e comunitários, por meio de ações coletivas e individuais para a disseminação de valores e atitudes orientadas na conservação ambiental e desenvolvimento sustentável a fim de enfrentar e superar os problemas socioambientais.

Existem várias definições do termo Educação Ambiental, dependendo da abordagem e do contexto histórico. Para Cascino (2003), a Educação Ambiental busca uma compreensão dos ambientes de maneira integrada e não excludente, privilegiando as relações de igualdade e respeito entre os indivíduos e o grupo no combate aos conflitos através do diálogo. Outra abordagem desse conceito elaborada por Santos (2009), apresenta a Educação Ambiental como à própria educação de caráter interdisciplinar e de cunho político vinculado à quebra de paradigmas e que através de uma nova concepção de pedagogia propõe a educação como forma de participação e reapropriação da natureza.

Segundo Carvalho (2012) a Educação Ambiental faz parte do movimento ecológico, pois agrega a preocupação da qualidade de vida das presentes e futuras gerações. Enquanto, Leff (2012) argumenta que a Educação Ambiental é um processo de conscientização socioambiental capaz 
de mobilizar os cidadãos na tomada de decisões e nas transformações a partir de uma visão integrada, holística e interdisciplinar.

A Educação Ambiental permite a discussão, a troca de experiências e a divulgação de práticas sustentáveis, pautadas na racionalidade e ética ambiental, que possibilitem a reconstrução dos paradigmas que moldam e governam a sociedade. A racionalidade ambiental é fruto da aliança entre as racionalidades, teórica, substantiva, instrumental e cultural, buscando a reorganização da produção baseada no potencial produtivo da natureza, condição necessária ao desenvolvimento sustentável, bem como baseasse em princípios éticos, respeito e harmonia com a natureza e valores culturais e políticos, calcadas na democracia participante, equidade social e respeito à diversidade ética e cultural (LEFF, 2012).

\section{Educação Ambiental aplicada em área cárstica de Tejuçuoca-Ceará}

A partir do diagnóstico dos problemas ambientais no carste Furna dos Ossos, realizou-se por um grupo de estudantes do curso de Geografia da Universidade Federal do Ceará-UFC, atividades de Educação Ambiental, com um grupo de moradores do Assentamento Macaco, voltadas a conscientização ambiental, valorização do semiárido e potencialização do desenvolvimento do turismo sertanejo em Tejuçuoca.

Primeiramente, realizou-se seminários sobre a Geografia do Sertão do Ceará (Figura 2), apresentando as bases naturais e físicas do ambiente, clima, solo, vegetação, geologia, relevo, enfatizando principalmente o município de Tejuçuoca e a geomorfologia do parque. Nessa atividade, foram abordados os conceitos e definições sobre carste, solos do Ceará, paisagem, vegetação da caatinga e condições climáticas do semiárido com o auxílio de mapas da área e apresentação de slides em power point. 


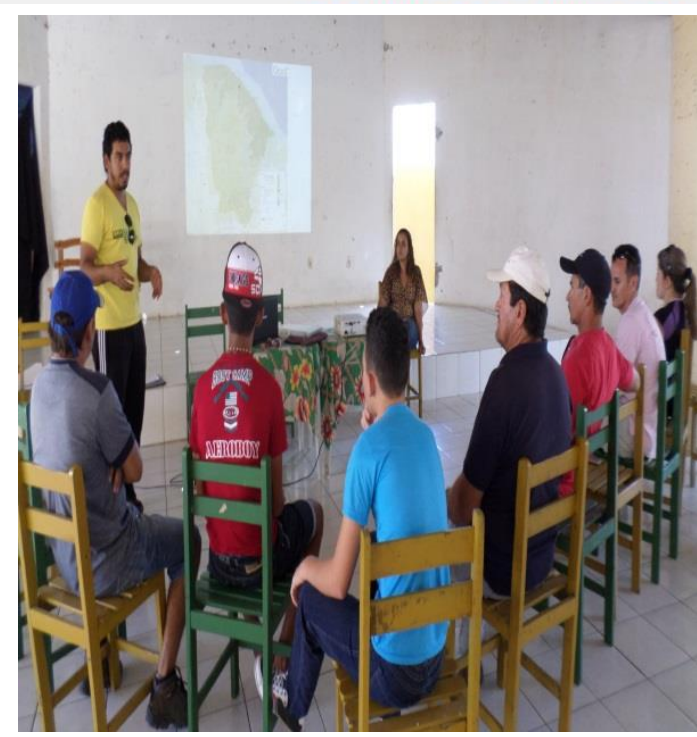

Figura 2- Seminário sobre Geografia do Ceará, Tejuçuoca.

Fonte- MOURA, 2014.

Em outro momento, se efetivou palestra e roda de conversa sobre a importância do manejo dos recursos naturais, conservação da caatinga, solo e água, com a participação dos moradores do assentamento que contribuirão para a interlocução entre os conhecimentos tradicionais e científicos. Abordaram-se principalmente, os prejuízos das queimadas para o solo e a vegetação, uso de fertilizantes e agrotóxicos, a definição de agroecologia e agrofloresta, os benefícios das matas ciliares para a manutenção da qualidade do rio. Segundo Silva e Vasconcelos (2012):

É através do diálogo entre os que possuem o saber empírico e os que possuem o saber científico que a estratégia de desenvolvimento mais adequada às regiões semiáridas cearenses será construída. É na junção do conhecimento dos agricultores e pesquisadores que se terá uma prática de educação ambiental adequada às necessidades socioambientais da região.

Ademais, efetivou-se a construção de matrizes ambientais com o auxilio de materiais simples: cartolinas e pinceis atômicos. Os moradores do assentamento foram divididos em grupos e tiveram 30 minutos para a discussão, debate e criação das matrizes ambientais elencando as potencialidades e fragilidades de Tejuçuoca, bem como propostas de soluções para os problemas ambientais diagnosticados a partir da interpretação das condições ambientais, sociais e históricas. Após esse primeiro momento, os grupos apresentaram aos demais, suas matrizes ambientais (Figura 3) permitindo o diálogo sobre as convergências e divergências nos resultados de cada grupo obtidos com a atividade. 


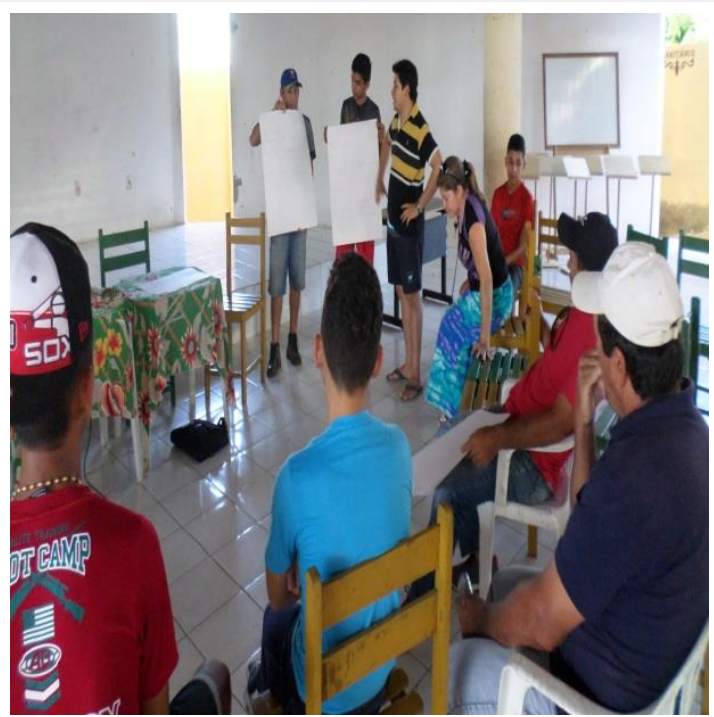

Figura 3- Apresentação das matrizes ambientais construídas pelos moradores do Assentamento Macaco, Tejuçuoca.

Fonte- MOURA, 2014.

As atividades foram embasadas na concepção de Educação Ambiental Étnico-Social descrita por Rodriguez e Silva (2013) que enfatizam a formação do indivíduo não apenas através do ensino formal, mas também pela aquisição de conhecimentos a partir da vivência do cotidiano e da educação informal. Nesse sentido, a construção das matrizes ambientais, como produto final, considerou-se o conhecimento prévio e a percepção ambiental dos envolvidos que indagados e instigados pelas atividades anteriores, seminários, palestra e roda de conversa puderam contrapor suas ideias sobre a utilização dos recursos naturais frente à importância da conservação e solução dos problemas ambientais diagnosticados a partir das potencialidades e fragilidades elencadas por eles.

O desenvolvimento dessas práticas de Educação Ambiental foi importante, pois permitiu a troca de saberes entre os envolvidos, servindo de ferramenta, não somente para a conscientização e conservação ambiental, mas também para a promoção dos saberes tradicionais na perspectiva do resgate e valorização desse conhecimento, bem como para o desenvolvimento comunitário.

A Educação Ambiental proporciona uma mudança nos valores e na postura das pessoas, fomentando novas atitudes nos sujeitos sociais e novas diretrizes para a implementação de políticas por parte dos governos. Nessa perspectiva, é importante sua utilização como instrumento estratégico no combate a degradação de ambientes vulneráveis à ocupação humana (SILVA; VASCONCELOS, 2012). 
Ademais, a parceria entre a Universidade e a população desse município contribuiu para que os residentes percebessem a importância da conservação dos recursos naturais e do reconhecimento de sua cultura como expressão legítima do modo de vida do sertanejo, bem como ofereceu subsídios para que os moradores do Assentamento Macaco, cientes das potencialidades naturais de Tejuçuoca, busquem meios para o desenvolvimento do turismo sertanejo, atividade pautada no trinômio: conservação ambiental, resgate cultural e inclusão social.

\section{Conclusão}

O sertão cearense, mesmo com características físicas limitantes, irregularidade das chuvas, solos rasos e pedregosos dentre outras, apresenta belas paisagens e rica cultura que representam nítidas potencialidades ao desenvolvimento de atividades turísticas pautadas no respeito à natureza, valorização das tradições sertanejas, difusão de conhecimento geográfico e o mais importante, multiplicação de valores, atitudes e comportamentos ecologicamente orientados na Educação Ambiental para a promoção de um ambiente mais sustentável e prospero.

A Educação Ambiental precisa ir além da discussão teórica e epistemológica dentro das Universidades, deve estar presente nas comunidades tradicionais, no meio informal, nas associações, junto às populações e alunos que poderão servir de multiplicadores ambientais das experiências e saberes adquiridos e trocados, aumentando os resultados, a sensibilização sobre o meio natural.

Nessa perspectiva, tem-se que as atividades desenvolvidas permitiram um novo olhar sobre o meio ambiente e seus recursos naturais, tanto por parte dos moradores do assentamento quanto dos estudantes de Geografia, pois permitiu o intercambio entres o conhecimento vivenciado, tradicional e o científico demonstrando a importância da ampliação das práticas de Educação Ambiental para a sensibilização e promoção de ideias sustentáveis na perspectiva da transformação da realidade e melhorias ambientais.

\section{REFERÊNCIAS}

ASSOCIAÇÃO CAATINGA. Conheça e Conserve a Caatinga: o bioma Caatinga. V. 1. Fortaleza: Associação Caatinga, 2012.

CARVALHO, I. G. de M. Educação Ambiental: A formação do sujeito ecológico. São Paulo-SP: Cortez, 2012.

CASCINO, F. Educação Ambiental: princípios, história, formação de professores. 3.ed. São Paulo: Editora Senac São Paulo, 2003.

CHISTOFOLETTI, A. Geomorfologia. 2.ed. São Paulo, Blucher, 2011. 
GUERRA, A. T. Dicionário Geológico-Geomorfológico. 4 ed. Rio de Janeiro: Instituto Brasileiro de Geografia, 1972.

IBGE. Censo Demográfico 2010: cidade de Tejuçuoca. Disponível em: http://cidades.ibge.gov.br/xtras/temas.php?lang=\&codmun=231335\&idtema=1\&search=ceara|tejucuoca|c enso-demografico-2010:-sinopse. Acesso em: 03, novembro, 2015

KOHLER, H. C. Geomorfologia cárstica. In: GUERRA, A. J. T.; CUNHA, S. B. da. Geomorfologia: uma atualização de bases e conceitos, 11 ed. Rio de Janeiro: Bertrand, 2012.

LEFF, E. Saber ambiental: sustentabilidade, racionalidade, complexidade, poder. 9 ed. Petrópolis (RJ): Vozes

LINO, C. F. Cavernas: o fascinante Brasil subterrâneo. 2 ed. São Paulo: Gaia, 2009.

MARCONI, M. A.; LAKATOS, E. M. Metodologia Científica. 6 ed. São Paulo: Atlas, 2011. 314 p.

PEREIRA, R. C. M; SILVA, E. V. da. Solos e vegetação do Ceará: características gerais. In: SILVA, J. B. da. et al (orgs.). Ceará: um novo olhar geográfico. 2 ed. Fortaleza: Edições Demócrito Rocha, 2007.

RODRIGUEZ, J. M. M.; SILVA, E. V. da. Educação Ambiental e Desenvolvimento Sustentável: problemáticas, tendências e desafios. 3 ed. Fortaleza: Expressão Gráfica e Editora, 2013.

SANTOS, E. da C. (org.). Geografia e Educação Ambiental: reflexões epistemológicas. Manaus-AM: Editora da Universidade Federal do Amazonas, 2009.

SEABRA, G. Turismo Sertanejo. João Pessoa: Editora Universitário UFPB, 2007.

Turismo Sertanejo: a cultura regional e o desenvolvimento local. In: SEABRA, G. (org.). Turismo de Base Local: identidade, cultura e desenvolvimento regional. João Pessoa: Editora Universitário UFPB, 2011.

SEABRA, Lícia. Turismo sustentável: planejamento e gestão. In: CUNHA, S. B. da; GUERRA, A. J. T. (org.) A questão ambiental: diferentes abordagens. 5 ed. Rio de janeiro: Bertrand Brasil, 2012.

SILVA, E. V. da. Ecoturismo, turismo rural e patrimônio cultural. In: SEABRA, G. (org.). Turismo de Base Local: identidade, cultura e desenvolvimento regional. João Pessoa: Editora Universitário UFPB, 2007.

SILVA, G. G. S. e; VASCONCELOS, P. F. Educação Ambiental como estratégia sustentável de convivência em áreas susceptíveis à desertificação no Estado do Ceará. In: FALCÃO SOBRINHO, J.; FIGUEIREDO, M.; COSTA FALCÃO, C. L.da. Meio ambiente e sustentabilidade no semiárido. Sobral (CE): Edições Universitárias, 2012.

SUGUIO, K. Dicionário de geologia sedimentar e áreas a fins. Rio de Janeiro, Bertande Brasil, 1998. 